\title{
Explain the Causal Model of the Use of Internet Technology by Employees of the National Bank of Shiraz, According to Subjective Norms, Governmental and Institutional Support
}

\author{
Fariba Tabe Bordbar, ${ }^{1,}$ Seyed Mohammad Hossein Kamani, ${ }^{2}$ and Mozhgan Yekta ${ }^{2}$ \\ ${ }^{1}$ Psychology, Department of Psychology and Educational Science, Literature and Humanities Faculty, Payame Noor, Tehran, Iran \\ ${ }^{2}$ Management, Department of Management, Literature and Humanities Faculty, Payame Noor, Tehran, Iran \\ "Corresponding author: Fariba Tabe Bordbar, Psychology, Department of Psychology and Educational Science, Literature and Humanities Faculty, Payame Noor, Tehran, Iran, \\ E-mail: yasaman72004@yahoo.com
}

Received 2015 July 15; Revised 2015 December 17; Accepted 2015 December 24.

\begin{abstract}
Background: Customers have not completely welcomed the use of e-banking. This study investigated the causal relationship of the use of Internet technology according to subjective norms, governmental and institutional support.

Methods: This study is a relative-description based on members of staff of the National Bank of Shiraz randomly selected from a cluster of 260 homes. The (PU) and (PEOU) questioner was used for perceived usefulness and perceived ease of use. The BI and BU questioner was used for behavior usage and behavior intention. finally, social norms (NS), government and institute support (GS and IS) were used. The validity and reliability of all was evaluated by Cronbach's (alpha) and factor analyzer. The structural equation modeling was achieved using LISREL software ( 8.8 version) for data analysis.

Results: The results show that SN has direct effect on PU and PEOU, and a direct effect on BI and BU. PU. Also, PU has direct effect on $\mathrm{BI}$ and PU, and indirect effect on BU. GS has direct and indirect effect on BU. IS has direct effect on PU and indirect effect on BI and BU $(\mathrm{P}<0.001)$.

Conclusions: In general, the proposed model enables managers to strategically frame their service about factors which utilize the internet directly or indirectly.
\end{abstract}

Keywords: Subjective Norms, Government, Support, Internet, Organization

\section{Background}

For two decades now the need for internet services and information technology (IT) in organizations, especially in banks has grown significantly. Communicating with international counterparts demands the use of IT and internet services (1). Internet services and the use of IT have helped banks to run their operations faster and more accurately. According to the International Telecommunication Union, one out of every four people in the world uses internet services. Majority of bank customers have no interests in using internet services. Therefore, the perceived cause of customers' resistance to internet services usage can help bank managers in decision making about increasing customers' interests (2).

With the emergence of IT and internet, researchers have developed models based on intention and desire for predicting acceptance behavior of technology. In this research, the main focus is on Davis' technology acceptance and Ajzen's planned behavior model. The most important reason for the development of technology acceptance models is the structure and feasibility power of acceptance which according to the technology acceptance model, per- ceived usefulness and ease of use will lead to an increased acceptance (3). Studies in fields of technology acceptance and environmental compliance showed the effect of perceived usefulness and ease of use as the main factors in technology acceptance. Davis also observed that perceived usefulness and perceived ease of use are significantly associated with each other (This claim has been emphasized by numerous studies) $(4,5)$.

According to this model, behavior usage will be affected by individuals' intention to use a specific system. The users' behavior will also be determined by the technology's perceived usefulness. Technically, Davis shows the importance of a person's perceptions of the usefulness of a particular technology and its ease of use in accepting a specific technology. Davis explained the perception of usefulness as the degree to which a person believes; using a particular system will improve his or her job. Likewise, perceiving the ease of use will be determined by the person's belief that using a particular system does not require a lot of effort (4). Perceiving the ease of use can be effective on behavioral intentions and converting them into behavior $(6,7)$. A person's intention is the individual's perception 
of a particular behavior (8). In other words, a person's intention is a possible mental situation that makes a connection between the individual and his or her action. Based on the theory of planned behavior, the intention to perform a behavior is dependent on the person's attitude toward the behavior. Indeed, a person's attitude affects behavior by transforming to behavioral wills. Since behavioral wills predict actual behaviors, measuring them is very important to business researchers $(9,10)$.

Behavior is defined as a visible act which is connected to the person's belief or intention. Behavior could lead to negative and positive feelings associated with action or observation. The belief or perception of users about technology, ease of use and usefulness is important. Users will believe that a technology is useful when they believe that it is easy to use. To increase the use of information technology, users should be convinced that computer is useful and easy to use. Although the effect of individuals' perceived ease of use can change in different situations. If users perceive the internet as useful for their job, they can still use it despite the possibility that it is a hard work. Therefore, perceived ease of use is described in the degree to which a person believes that using a particular technology will be without any efforts $(10,11)$.

Some of the research's results show the effect of subjective norms on usage behavior and perceived ease of use (7, 10-12). In these researches, normal beliefs are considered as a variable situation that may take effect from the belief of friends, family, co-workers, and social groups. To clarify ambiguities and connection between subjective norms and usage behavior it is expected that a stronger social effect would lead to acceptance of technologies such as the internet. Some findings indicate that subjective norm will affect information technology (11-13). Users believe that the more they use IT - the more they earn profits. In places where members of staff are forced to use the internet or situations where they were under pressure by their colleagues to use the internet, the effects of subjective norms will increase. Results show that when the social pressure to use technology in organizations increases, it is more likely that the staff will believe that technology is useful and it can improve their job performance (14). This result is not supported in some of the researches (15).

Organizational support is one of the uses of the social exchange theory, included in the literature of organization theory (16). In the last two decades, there have been numerous attempts to analyze the nature and formation of organizational support. In addition, another part of the researches has been dedicated to evaluate the effects and consequences of organizational support in the areas of individuals, organizations, and career (17). The supportive behavior of leaders and also organizational atmosphere, can lead to perceived organizational support that is based on the people's extended beliefs and feelings about the organization's concerns on the future happiness of the organization's staff. Therefore, the role of government and institutional support in encouraging Iranian users is vital. In organizations, important decisions about technology and innovation is taken by management. According to Lewis, persons who use technology in these organizations are rarely taken into consideration. Therefore in this situation, peoples' intentions, needs and their reasons for resistance against the use of technology should be taken into consideration by the management (17).

The conceptual model used in this study is based on the planned theoretical behavior model of Ajzen and Davis' technology acceptance model developed by Venktash. In some previous studies, the limitation of these models was validated according to social and intrapersonal variables. Although in developing this model, Abbasi added two variables of organizational and governmental support (16). Along with the international community in application of the new findings to solve the problems and create indigenous knowledge according to Iranian culture, this model was examined in the cultural context of the Iranian national bank.

According to what was said in this study and in order to identify the causal model of internet technology acceptance by the staff of Shiraz national bank and from subjective norm variables, governmental and organizational supports has been done to gather valuable information for bank managers to choose a correct method for better internet usage quality.

To evaluate causal relationship based on correlation, independent variables were introduced as exogenous factors. Subjective norm is the original exogenous variable that is considered to directly affect perceived usefulness, ease of use and behavioral intention. It can also indirectly affect internet usage and organizational support. Perceived usefulness and ease of use directly affects internet usage and behavioral intention. Organizational and governmental support can directly affect perceived usefulness and internet usage and can also indirectly affect behavioral intention. These relationships are shown in Figure 1.

\section{Methods}

This research is a descriptive-relative study. The statistical population of Shiraz National Bank consists of 800 people. With the use of Morgan table, samples of 260 members of staff were chosen cluster style. In this study, ethics and legal rules were applied. In order to collect data, ensure accuracy and quality of the received data, the aims and im- 


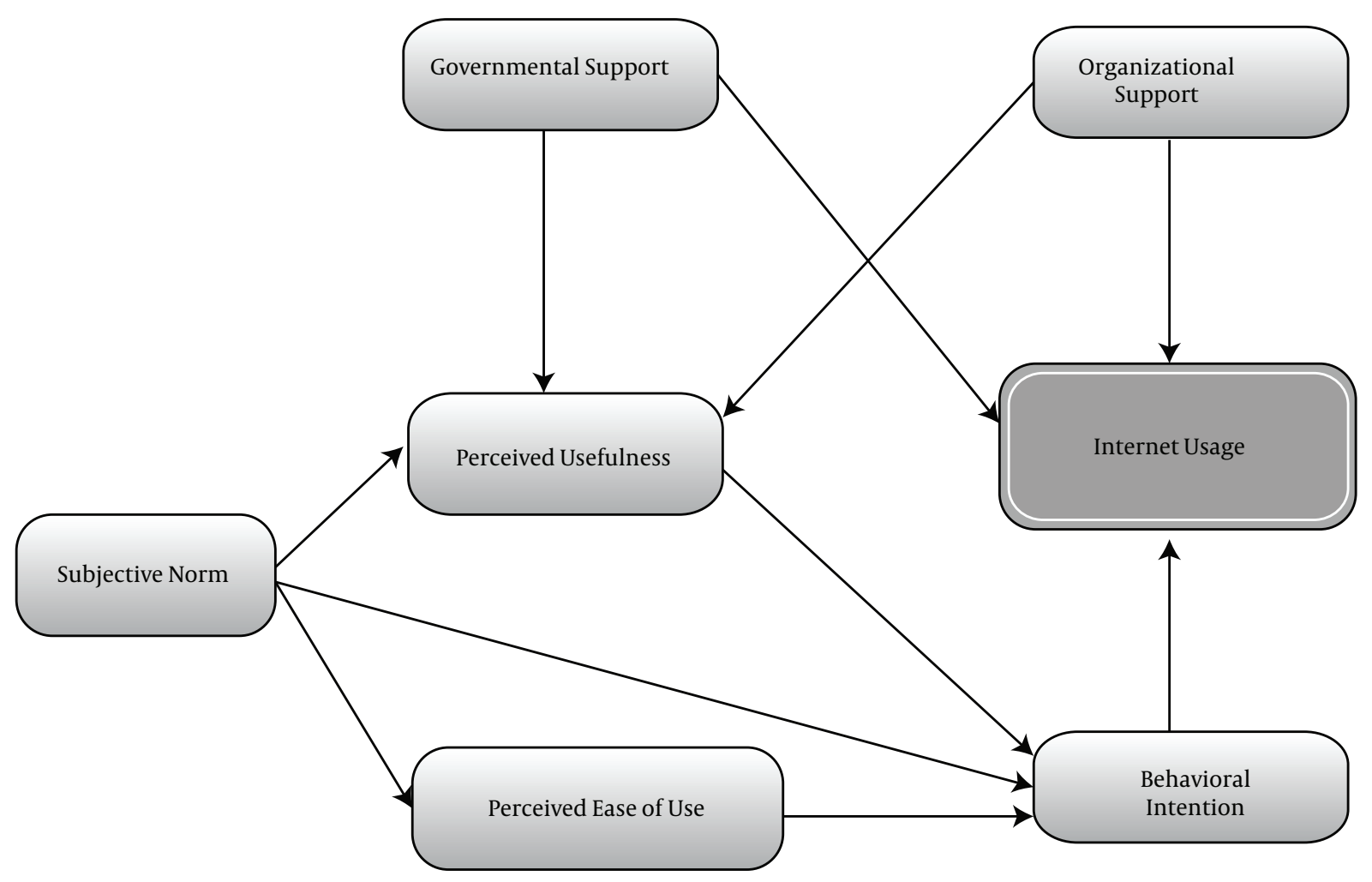

Figure 1. The Purposed Model (16)

portance of the research were explained to the group in the first stage also writing the name of the attendant was not compulsory. The attendant should be one of the bank's employee and be directing in touch with the bank's online system. To evaluate ease of use and perceived usefulness, Venktash's questionnaire with 9 questions was used (4 questions for ease of use and 5 questions for perceived usefulness) (10). Ball and Venkatesh's questionnaire was used for internet usage and behavioral intentions with 8 questions. All of them were measured on the Likert five point scale (10). A questionnaire by Lewis et al. was used for social norms (5 questions), governmental support (8 questions), and organizational support (7 questions) (16). Validity and reliability was measured as good. In general Content validity refers to how accurately an assessment or measurement tool taps into the various aspects of the specific construct in question. In other words, do the questions really assess the construct in question, or are the responses by the person answering the questions influenced by other factors.

Face and Content validity of the questionnaires were determined by 5 experts that familiar to management systems through the content validity. In final they have high agreement about adequacy of test responses. First, two indices of Bartlett and KMO were evaluated. The KMO correlation matrix was 0.9 and it was acceptable. Bartlett for adequacy examination was 5156.530, significance in $\mathrm{P}$ value $=$ 0.001 .

The Cronbach's alpha method was used for reliability test. This index shows the internal reliability which was achieved for governmental support (0.89), organizational support (0.88), subjective norm (0.88), perceived usefulness (0.88), ease of use (0.88), behavioral intentions (0.88), and internet usage (0.88). Data was analyzed by version 8.8 of the LISREL software.

\section{Results}

Prior to analytical tests, normal distribution of scores was confirmed with the Kolmogorov-Smirnov test.

Table 1 shows the Pearson correlation matrix between variables and their means. According to this, the relationship between most of the variables was significant. These coefficients show the relation between external, intermediate, and internal variables. The highest mean is related 
to the subjective norm $(M=2.71)$ while the lowest mean is related to the perceived ease of use $(M=2.6)$.

Path analysis is one of the strongest ways of multiple variable analyses. One of the most important software for this analysis is the LISREL software. Variables in causal modeling can be evaluated in three ways: the exogenous variables (that are independent of other variables), Endogenous variables (that are dependent on one or more variables) and mediated variables (that affect the relation between an independent and a dependent variable). This effect was calculated directly, indirectly, and totally.

Direct effect: According to Table 2, subjective norm is the first exogenous variable having a positive effect on perceived usefulness (0.11) and perceived ease of use (0.81), but does not have a direct meaningful relation with behavioral intention. Perceived usefulness as the second exogenous variable has a direct meaningful relation with behavioral intention (0.93) and internet usage (0.55).

Perceived ease of use, as the third exogenous variable, has a direct meaningful relation only with behavioral intention (0.23). The forth exogenous variable is governmental support and has a positive meaningful effect on perceived usefulness (0.88), but it has no effect on internet technology. Organizational support as the fifth exogenous variable has a direct positive effect on perceived usefulness (0.29). Behavioral intention as the final exogenous variable has a direct meaningful effect on internet usage (0.44).

As previously noted, in path analysis, indirect effects of variables are computable. This calculation can help to identify factors affecting the relation between variables.

Indirect relation: According to Table 3, subjective norm indirectly affect behavioral intention (0.29) and internet usage $(0.20)$ by affecting perceived usefulness and ease of use. Perceived ease of use has an indirect meaningful relation with internet usage $(0.10)$ by affecting behavioral intention. As a result of perceived usefulness, governmental support could have an indirect meaningful relation with behavioral intention (0.82) and internet usage (0.85). Considering the high correlation of the two latter variables, the high effect of governmental support with perceived usefulness can be effective. By affecting perceived usefulness, organizational support has an indirect effect on behavioral intentions and internet usage, but behavioral intention does not have any indirect effect on internet usage.

Total relations: Total effect is calculated by sum of direct and indirect effect. Calculation of total effect can distinguish the fundamental role of each variable with attention to the final coefficient. This coefficient can facilitate model correction and placement in the final stage of the process.

From Table 4, exogenous variables such as perceived usefulness, governmental support, subjective norms, or- ganizational support, behavioral intention, and perceived ease of use, respectively, have the highest total effect on their endogenous variables. The first two variables, coefficients indicate the two most important variables in Iranian banking, as perceived usefulness of technology and governmental support.

To evaluate the overall goodness of fit, a model using fit indexes was utilized. The ratio of Chi-Square to the degree of freedom is 1.73 and was regarded as good. Goodness of fit index (GFI), Adjusted goodness of fit index (AGFI), Comparative fit index (CFI), Normed fit index (NFI), Relative fit index (RFI) and Root mean square error of (RMSEA) greater than or equal to 0.90 for (GFI, NFI, RFI, CFI) indicates a good model fit. RMSEA values ranging from 0.05 to 0.08 are acceptable; therefore the RMSEA suggested that our model fit was acceptable.

In the final model, a direct path of SN on BI, GS and OS on IS is not significant and an indirect relationship was recorded.

\section{Conclusion}

Findings from path analyses emphasized on the effective variables of internet usage which shows that all of them played a critical role. Due to the widespread usage of various communities of IT and internet, different social, economic, political, and cultural dimensions of these technologies and their effects should be considered.

In agreement with the pioneers, Ajzen, Venkatesh, and Taylor, this study shows that subjective norms cannot directly affect internet usage. Social behavior activists should affect user's behavioral intention and technology usage by changing attitudes in perceived usefulness and perceived ease of use $(9,10,12)$.

Study results show that accepting technology is influenced by the user's beliefs which are related to his or her surroundings. These effects can cause a change in a person's belief in technology and its usage. From the indirect effects of governmental support on internet usage, it can be understood that in Iranian culture, governmental support plays an important role in changing people's belief about perceived usefulness and ease of use of IT. This result is supported by several studies $(15,16)$. The supportive behavior of management can increase a user's sense of organizational support and job responsibility. It can also make organizational changes acceptable. Perceived usefulness compared with perceived ease of use has a more direct and indirect relationship with internet usage. This result is similar to Ajzen, Taylor, Todd, and Eze's studies $(4,6,12)$. If users perceive organizational changes as useful, they will accept changes more easily. Chen believed that by changing the beliefs in perceived usefulness and ease of use, it be- 
Table 1. Correlation Matrix of External, Internal and Intermediate Variables

\begin{tabular}{|c|c|c|c|c|c|c|c|c|c|}
\hline Variable & Mean & Standard Deviation & 1 & 2 & 3 & 4 & 5 & 6 & 7 \\
\hline Governmental support & 2.64 & 0.99 & 1 & & & & & & \\
\hline Organizational support & 2.65 & 0.84 & 0.23 & 1 & & & & & \\
\hline Subjective norm & 2.71 & 0.73 & 0.21 & 0.011 & 1 & & & & \\
\hline Perceived usefulness & 2.63 & 0.91 & $0.95^{\mathrm{a}}$ & $0.90^{\mathrm{a}}$ & $0.84^{\mathrm{a}}$ & 1 & & & \\
\hline Perceived ease of use & 2.60 & 0.95 & $0.95^{\mathrm{a}}$ & $0.95^{\mathrm{a}}$ & $0.81^{\mathrm{a}}$ & $0.95^{\mathrm{a}}$ & 1 & & \\
\hline Behavioral intention & 2.64 & 0.92 & $0.84^{\mathrm{a}}$ & 0.012 & 0.02 & $0.95^{\mathrm{a}}$ & $0.97^{\mathrm{a}}$ & 1 & \\
\hline Internet usage & 2.63 & 0.91 & $0.95^{\mathrm{a}}$ & $0.90^{\mathrm{a}}$ & 0.018 & $0.95^{\mathrm{a}}$ & 0.045 & $0.98^{\mathrm{a}}$ & 1 \\
\hline
\end{tabular}

${ }^{\mathrm{a}}$ Significance level is important in the level of 0.01 .

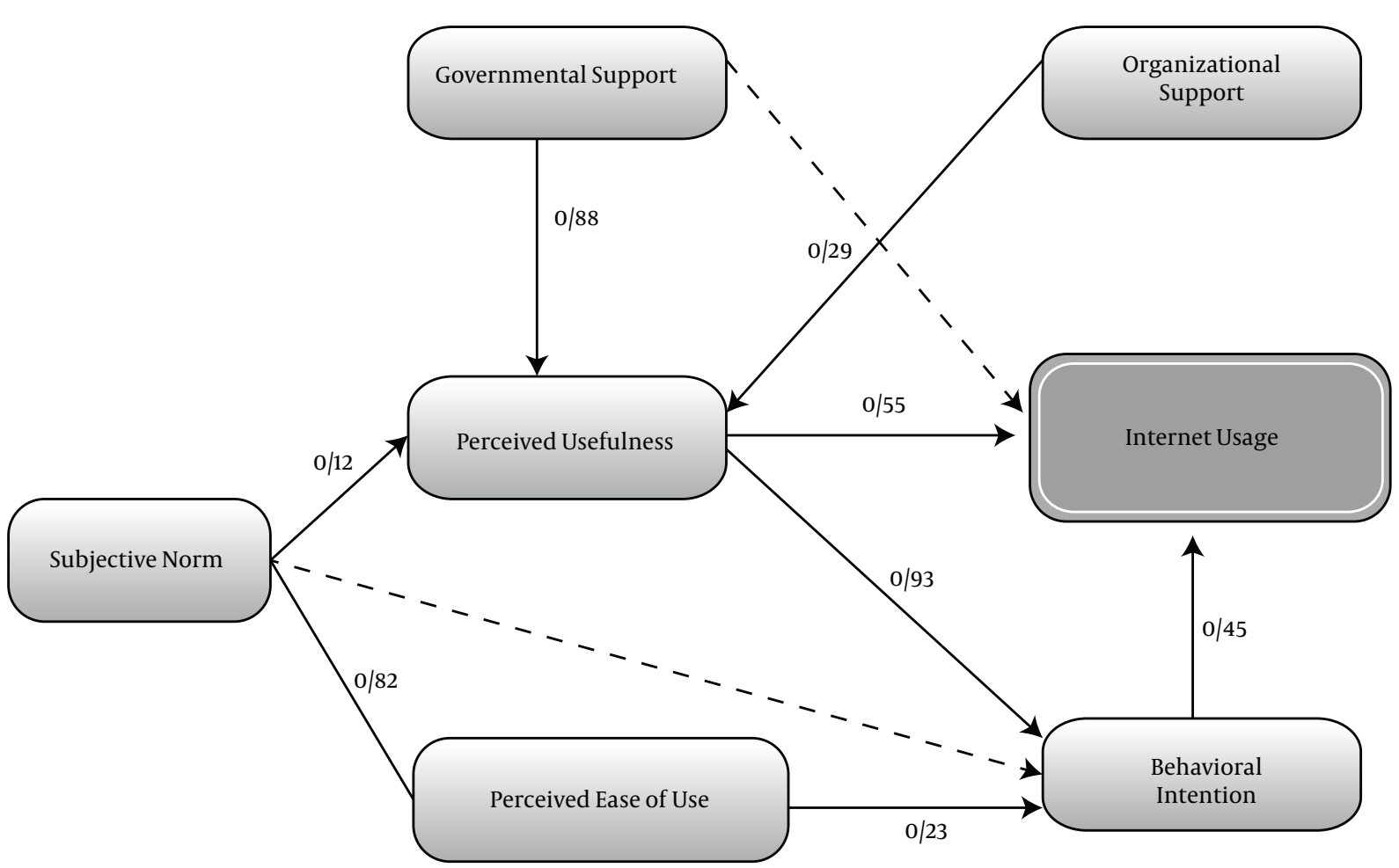

Figure 2. Final Model

comes possible to achieve this change (14). Abbasi, Lee, and Turner achieved the same results $(5,15,16)$. Considering the powerful role of subjective norms in creating changes, managers should be aware of this role.

The suggested model has specific theoretical and practical applications. Theoretically, by merging the main elements of available models, there would be increased model predictability in choosing effective variables and predicting their behaviors. As this model is created using an advanced structural equation model, it can be applied in the real world. This model can determine both positive and negative factors which are effective in the acceptance of new informational systems by users according to their culture. Identifying and strengthening the positive factors (especially subjective norms which is this study's finding) can accelerate the effectiveness of technology usage. One of the limitations of this study, despite data analysis done by structural equation modeling, is that the interpretation of results as the cause and effect relationship has its weakness. Lack of attention to cognitive, cultural, and psychological variables like development, success, and failure is another limitation of this study. The next limitation is the use of a questionnaire instead of interview or observation. It is recommended that the examination of this model should be repeated in universities and other governmental or private organizations with the use of better 
Table 2. Estimates of the Direct Effect Coefficient

\begin{tabular}{|c|c|c|}
\hline \multirow[t]{2}{*}{ Variables } & \multicolumn{2}{|c|}{ Estimates } \\
\hline & $\begin{array}{l}\text { Standardized } \\
\text { parameter }\end{array}$ & Significance level \\
\hline \multicolumn{3}{|l|}{$\begin{array}{l}\text { Direct effect of } \\
\text { subjective norms on }\end{array}$} \\
\hline $\begin{array}{l}\text { Perceived } \\
\text { usefulness }\end{array}$ & 0.119 & 0.01 \\
\hline $\begin{array}{l}\text { Perceived ease of } \\
\text { use }\end{array}$ & 0.815 & 0.006 \\
\hline $\begin{array}{l}\text { Behavioural } \\
\text { intention }\end{array}$ & 0.023 & 0.147 \\
\hline \multicolumn{3}{|l|}{$\begin{array}{l}\text { Direct effect of } \\
\text { perceived usefulness } \\
\text { on }\end{array}$} \\
\hline $\begin{array}{l}\text { Behavioural } \\
\text { intention }\end{array}$ & 0.933 & 0.031 \\
\hline Internet usage & 0.551 & 0.003 \\
\hline \multicolumn{3}{|l|}{$\begin{array}{l}\text { Direct effect of } \\
\text { perceived ease of use } \\
\text { on }\end{array}$} \\
\hline $\begin{array}{l}\text { Behavioural } \\
\text { intention }\end{array}$ & 0.230 & 0.003 \\
\hline \multicolumn{3}{|l|}{$\begin{array}{l}\text { Direct effect of } \\
\text { governmental support } \\
\text { on }\end{array}$} \\
\hline $\begin{array}{l}\text { Perceived } \\
\text { usefulness }\end{array}$ & 0.883 & 0.01 \\
\hline Internet usage & 0.011 & 0.452 \\
\hline \multicolumn{3}{|l|}{$\begin{array}{l}\text { Direct effect of } \\
\text { organizational } \\
\text { support on }\end{array}$} \\
\hline $\begin{array}{l}\text { Perceived } \\
\text { usefulness }\end{array}$ & 0.292 & 0.004 \\
\hline Internet usage & 0.005 & 0.446 \\
\hline \multicolumn{3}{|l|}{$\begin{array}{l}\text { Direct effect of } \\
\text { behavioural intention } \\
\text { on }\end{array}$} \\
\hline Internet usage & 0.445 & 0.02 \\
\hline
\end{tabular}

qualitative methods and by placing variables such as motivational factors to facilitate the admission.

\section{Acknowledgments}

The authors wish to acknowledge all students and professors of e-learning courses at Iran University of Science and Technology, K.N.Toosi University of Technology, Olumo Hadis University of Ray and Mehralborz University.

\section{Footnotes}

Author's Contribution: We ask authors to describe what each author contributed, and these contributions to the
Table 3. Estimates of the Indirect Effect Coefficient

\begin{tabular}{|c|c|c|}
\hline \multirow[t]{2}{*}{ Variables } & \multicolumn{2}{|c|}{ Estimates } \\
\hline & $\begin{array}{l}\text { Standardized } \\
\text { parameter }\end{array}$ & Significance level \\
\hline \multicolumn{3}{|l|}{$\begin{array}{l}\text { Indirect effect of } \\
\text { subjective norms on }\end{array}$} \\
\hline $\begin{array}{l}\text { Behavioural } \\
\text { intention }\end{array}$ & 0.229 & \\
\hline Internet usage & 0.209 & 0.006 \\
\hline \multicolumn{3}{|l|}{$\begin{array}{l}\text { Indirect effect of } \\
\text { perceived usefulness } \\
\text { on }\end{array}$} \\
\hline Internet usage & 0.415 & 0.02 \\
\hline \multicolumn{3}{|l|}{$\begin{array}{l}\text { Indirect effect of } \\
\text { perceived ease of use } \\
\text { on }\end{array}$} \\
\hline Internet usage & 0.102 & 0.005 \\
\hline \multicolumn{3}{|c|}{$\begin{array}{l}\text { Indirect effect of } \\
\text { governmental support } \\
\text { on }\end{array}$} \\
\hline $\begin{array}{l}\text { Behavioural } \\
\text { intention }\end{array}$ & 0.824 & 0.01 \\
\hline Internet usage & 0.854 & 0.001 \\
\hline \multicolumn{3}{|l|}{$\begin{array}{l}\text { Indirect effect of } \\
\text { organizational } \\
\text { support on }\end{array}$} \\
\hline $\begin{array}{l}\text { Behavioural } \\
\text { intention }\end{array}$ & 0.237 & 0.004 \\
\hline Internet usage & 0.283 & 0.003 \\
\hline
\end{tabular}

work may be published at the editor's discretion. Example: Author Contributions: Study concept and design: Fortes, Melchi, and Abeni. Analysis and interpretation of data: Fortes, Mastroeni, and Leffondre. Drafting of the manuscript: Fortes. Critical revision of the manuscript for important intellectual content: Mastroeni, Leffondre, Sampogna, Melchi, Mazzotti, Pasquini, and Abeni. Statistical analysis: Fortes and Mastoeni. Example: Yoon Kong Loke developed the original idea and the protocol, abstracted and analyzed data, wrote the manuscript, and is guarantor. Deirdre Price and Sheena Derry contributed to the development of the protocol, abstracted data, and prepared the manuscript.

Conflict of Interests: To prevent the information on potential conflict of interest for authors from being overlooked or misplaced, mention this information in the cover letter. Authors must identify any potential financial conflicts of interest before the review process begins. Declared conflict of interest will not automatically result in rejection of paper but the editors reserve the right to publish any declared conflict of interest alongside accepted. The following would generally be regarded as potential 
Table 4. Estimates of the Total Effect Coefficient

\begin{tabular}{|c|c|c|c|c|}
\hline Variables & Direct effects & Indirect effects & Total effects & Significance level \\
\hline \multicolumn{5}{|l|}{ Subjective norm on } \\
\hline Perceived usefulness & 0.11 & - & 0.11 & 0.001 \\
\hline Perceived ease of use & 0.81 & - & 0.81 & 0.001 \\
\hline Behavioural intention & 0.023 & 0.29 & 0.39 & 0.001 \\
\hline Internet usage & - & 0.20 & 0.20 & 0.001 \\
\hline \multicolumn{5}{|l|}{ Perceived usefulness on } \\
\hline Behavioural intention & 0.93 & - & 0.93 & 0.001 \\
\hline Internet usage & 0.55 & 0.41 & 0.96 & 0.001 \\
\hline \multicolumn{5}{|l|}{ Perceived ease of use on } \\
\hline Behavioural intention & 0.23 & - & 0.23 & 0.001 \\
\hline Internet usage & - & 0.10 & 0.10 & 0.001 \\
\hline \multicolumn{5}{|l|}{ Governmental support on } \\
\hline Perceived usefulness & 0.88 & - & 0.88 & 0.001 \\
\hline Internet usage & 0.011 & 0.85 & 0.86 & 0.001 \\
\hline Behavioural intention & - & 0.82 & 0.82 & 0.001 \\
\hline \multicolumn{5}{|l|}{ Organizational support on } \\
\hline Perceived usefulness & 0.29 & - & 0.29 & 0.001 \\
\hline Internet usage & 0.005 & 0.28 & 0.28 & 0.001 \\
\hline Behavioural intention & - & 0.27 & 0.27 & 0.001 \\
\hline \multicolumn{5}{|l|}{ Behavioural intention on } \\
\hline Technology usage & - & - & 0.44 & 0.001 \\
\hline
\end{tabular}

Table 5. Goodness Fit Indexes

\begin{tabular}{lcc}
\hline Index & Value & Result \\
\hline Chi-Square to the degree of freedom $\left(\mathbf{x}^{\mathbf{2}} / \mathbf{d f}\right)$ & 1.37 & $2.5<$ \\
\hline Comparative fit index $(\mathbf{C F I})$ & 0.93 & $0.9<$ \\
\hline Goodness of fit index $(\mathrm{GFI})$ & 0.96 & $0.9<$ \\
\hline Adjusted goodness of fit index (AGFI) & 0.91 & $0.9<$ \\
\hline Root mean square error (RMSEA) & 0.07 & $<0.1$ \\
\hline
\end{tabular}

conflicts of interest: 1 . direct financial payment to an author for the research or manuscript production by the sponsor of a product or service evaluated in an article. 2 . Ownership of shares by an author in the company sponsoring a product service evaluated in an article (or in a company sponsoring a competing product). 3. Personal consultant for companies or other organizations with a financial interest in the promotion of particular health care products and services.

\section{References}

1. Applegate LM, McFarlan FW, McKenney JL. Corporate information systems management. Irwin, Chicago, IL: Text and Cases; 1996.

2. Kuisma T, Laukkanen T, Hiltunen M. Mapping the reasons for resistance to Internet banking: A means-end approach. Int Inform Manage. 2007;27(2):75-85. doi: 10.1016/j.ijinfomgt.2006.08.006.

3. Davis FD. Perceived usefulness, perceived ease of use, and user acceptance of information technology. MIS Quarterly. 1989;13(3):319-40. doi: $10.2307 / 249008$.

4. Ajzen I. The theory of planned behavior. Organ Behav Hum Decis Process. 1991;50(2):179-211. doi: 10.1016/0749-5978(91)90020-t.

5. Turner M, Kitchenham B, Brereton P, Charters S, Budgen D. Does the technology acceptance model predict actual use? A systematic literature review. Inf Softw Technol. 2010;52(5):463-79. doi: 10.1016/j.infsof.2009.11.005.

6. Eze Uchenna C, Manyeki Jeniffer K, Yaw Ling H, Har lee C, editors. Factor's affecting internet banking adoption among young adults: evidence from Malaysia. International conference on social science and Humanity. 2011; pp. 377-81.

7. Khanifar H, Mohaghegh Niya MJ, Jandaghi GR, Molavi Z, Emami M. Factors influencing the intendancy of e- banking: an integration of TAM \& TPB with e- service quality. J Appl Sci. 2012;8(3):1842-52.

8. Yaghoubi NM, Bahmani E. Factors affecting the adoption of online banking-an integration of technology acceptance model and theory of planned behavior. Int J Bus Manag. 2010;5(9):159-65. doi: 10.5539/ijbm.v5n9p159. 
9. Ajzen I, Fishbein M. Understanding attitudes and predicting social behavior. Englewood Cliffs, NJ: Prentice-Hall; 1980.

10. Venkatesh V, Bala $H$. Technology acceptance model 3 and a research agenda on interventions. Decis Sci. 2008;39(2):273-315. doi: 10.1111/j.1540-5915.2008.00192.x.

11. Shyu SHP, Huang JH. Elucidating usage of e-government learning: A perspective of the extended technology acceptance model. Gov Inf $Q$. 2011;28(4):491-502. doi:10.1016/j.giq.2011.04.002.

12. Taylor S, Todd PA. Understanding information technology usage: A test of competing models. Inf Syst Res. 1995;6(2):144-76. doi: 10.1287/isre.6.2.144.

13. Hu PJ, Chau PYK, Sheng ORL, Tam KY. Examining the technology acceptance model using physician acceptance of telemedicine technology. J Manage Inform Syst. 2015;16(2):91-112. doi: $10.1080 / 07421222.1999 .11518247$
14. Chen L, Gillenson ML, Sherrell DL. Enticing online consumers: an extended technology acceptance perspective. Inform Manage. 2002;39(8):705-19. doi:10.1016/s0378-7206(01)00127-6.

15. Lee MC. Factors influencing the adoption of internet banking: An integration of TAM and TPB with perceived risk and perceived benefit. Electron Commer Res Appl. 2009;8(3):130-41. doi: 10.1016/j.elerap.2008.11.006.

16. Sharif Abbasi M, Hussain Chandio F, Fatah Soomro A, Shah F. Social influence, voluntariness, experience and the internet acceptance. J Enterprise Inform Manage. 2011;24(1):30-52. doi: 10.1108/17410391111097410.

17. Lewis W, Agarwal R, Sambamurthy V. Sources of influence on beliefs about on formation technology use: an empirical study of knowledge workers. Mis Quarterly. 2003;27(4):657-78. 